\title{
The Management of Inter-Ethnic Relations in Germany and the United States: The Experience of the Theoretical Comprehension
}

\author{
Andrei Vladimirovich Bedrik ${ }^{1}$ \\ Igor Pavlovich Chernobrovkin²
}

\begin{abstract}
Alexander Konstantinovich Degtyarev³
\end{abstract}
Anton Vladimirovich Serikov 4

Nikita Andreevich Vyalykh ${ }^{5}$

\begin{abstract}
${ }^{1}$ Southern Federal University, Rostov-on-Don, Russian Federation 2Southern Federal University, Rostov-on-Don, Russian Federation ${ }^{3}$ Southern Federal University, Rostov-on-Don, Russian Federation ${ }^{4}$ Southern Federal University, Rostov-on-Don, Russian Federation ${ }^{5}$ Southern Federal University, Rostov-on-Don, Russian Federation Email: aserikov@inbox.ru
\end{abstract}

\section{Doi:10.5901/mjss.2015.v6n4s4p87}

\begin{abstract}
This article shows that inter-ethnic relations create consequences in strengthening the ethno-cultural heterogeneity of society, in ethnic enclavization, in the growth of inter-ethnic tension, demonstrated in various conflicts. The authors show that the apparent reason for refusal from the inter-ethnic relations management is the negation of inter-ethnic tension, more preciselyits transference into the discourse of cultural differences. Evaluating the ethnic conflict atmosphere in Russian society, as well as identifying ways to optimize the ethnic relations, requires no recognition of the Russian ethnic practices specialness. It is important to understand the comparability of Germany and the United States' experience, aiming at identifying the boundaries of introduction of management models based on the constructivism positions in the Russian society.
\end{abstract}

Keywords: inter-ethnic relations, policy, management of interethnic relations, ethnicity, identity, Germany, the United States.

\section{Introduction}

At the first glance, it is problematic to say that there is a query on the models of ethnic processes management in the United States and Germany, because the American society is concerned about the racial and ethnic relations and migration flows, while the migration problem and the ethnic Germans reintegration are equally essential for Germany.

Meanwhile, the inter-ethnic relations affect the strengthening of social ethno-cultural heterogeneity, ethnic enclavization, the growth of inter-ethnic tension, demonstrated in conflicts, often veiled with allegedly cultural and religious differences.

It is obvious that under the prevailing constructivist approach, which denies any "suspicions" in primordialism, interethnic processes management is presented beyond institutionalization, the establishment of governance structures and the emphasis is on the free choice of identity. In the situation when the identity is declared to have a key role in interethnic relations and variability and ambivalence are attributed to it, the problem of inter-ethnic processes management is conceived in the discourses of decentralization, initiative groups of citizens or cultural traditions consolidation.

Thus, the apparent reason for the refusal to manage inter-ethnic relations is the negation of inter-ethnic tension, more precisely, its transference into the discourse of cultural differences. Hence, the control objects are not ethnic communities but ethno-cultural groups that are constructed and reconstructed during the conflict or cooperation in the society. An integral element in the study of ethnicity becomes the preventive nature of ethno-nationalism, the desire to make a positive scenario of constructing a political nation, which includes integration on the basis of common civil virtues.

It would seem, we are dealing with a completely different situation, compared to Russia, but the evaluation of ethnic conflict potential in the Russian society, as well as identifying ways of the ethnic relations optimization, requires no recognition of the specialness of Russian ethnic practices. Tt is important to understand the comparability of Germany 
and the United States' experiences in order to identify the boundaries of introduction in the Russian society, concerning management models based on the constructivism positions.

\section{Literature Review}

Inter-ethnic relations management has different background parameters in the United States and Germany. The point is that the experience of post-war denazification of Germany enforced a taboo on inter-ethnic relations, which were not introduced into the public discourse, because of the inadmissibility of a return to nationalism. For the United States, the current system of legal regulation, which indicates that it is impossible to create the groups according to the ethnic classification, also had an anti-extremist sense. However, since the mid 70-ies of XX century one can talk about turning to the problems of inter-ethnic relations. It should be borne in mind that for Germany an ethnic enclavization has become the reality, 'Gastarbeit' effect, a 'temporary stay' effect has changed into the process of diasporization in the country (Turkish, Kurdish, Yugoslav).

The theoretical thought, one might say, turned out to be "caught by surprise" because ethnicity was interpreted as an archaic tradition and the idea of europeism was preserved for the German society.

Ethnic groups with structured hierarchical relations, with the ethnic identity were considered an obstacle, preventing the European integration, which converted the ethnic relations into the perspective of the incompatibility of the lifestyles and brought to the need-though a bearable one-of a coherent integration.

The integration project presumed "others" entering the context of the European (German) culture through the language assimilation and optimization of inter-ethnic communication, aiming at the substitution of "hereditary" ethnic identity by the "transitional" one, related to the possibilities of the second and third generations entering the host society. At the height of the 90-ies of the twentieth century, it became apparent that a high demographic increase in the ethnic communities, as well as the "faith" in the ethnic identity preservation, requires adjusting the inter-ethnic relations.

Although the term "management of interethnic relations" is absent from the official discourse, in recognition of the fact that Germany has become an ethnically mixed state contributed to the formation of inter-ethnic dialogue models: the main goal is to establish a system of interethnic communication via definition of "common interests and common threats", especially at the community level.

Thus, however "artificial", determined by the logic of globalization the problem of ethnic heterogeneity is, the German society has the inter-ethnic relations as a reality that goes beyond the migration perspective, because it is a daily reality of various ethnic communities co-existence. The concept of inter-ethnic dialogue and interethnic communication is based on the views of German sociologists (Darendorf, 2003). As for the theory of the medium level, a certain gap between the availability of existing community (local) projects and the definition of the scope of inter-ethnic relations management is obvious.

J. Delanty (Delanty, 2006), J. Haynes (Haynes, 2005), L. Diamond (Diamond, 1999) conclude that the practices of establishing the ethnic dialogue and ethnic communication focus on the refusal from the non-colonizational discourse. However, it should be noted that there is a problem of cultural colonization, which creates obstacles in the form of cultural - linguistic rejection and reproduces the situation of cultural distancing as a "bad infinity". In spite of the economic wellbeing, social obligations and practices of legal tolerance, German scientists recognize the irony of the situation in that the intention to decolonize their society may generate the inclusion of ethnic communities under the influence of the "romanticizing" policy.

The researches of inter-ethnic relations in Russia determine interest to the German experience, firstly, because the process of "internal decolonization", associated with constant criticism of the "Great State" heritage is far-fromunconditional. Secondly-and this is important for determining the content and objectives of the inter-ethnic relations management in Russia - an inter-ethnic dialogue and interethnic communication cannot have effective consequences, if not to take into account that the imperative of territoriality creates a different emphasis in the inter-ethnic relations, associated with the inter-ethnic dialogue formula for removing the very notion of a "colonial situation", which contains the implementations about the Imperial past being not yet overcome.

\section{Methodology}

Assuming that the goal of the research is the conceptualization of ethnic relations control, it could seem attractive to use the terminology of management sociology. However, there are certain limitations associated with the semantics of "management": in order to understand the stated perspective it is important to focus on the communicative paradigm, including the possibility of reconstruction of models of governance exchange and comparison. These models cannot be 
classified solely on the basis of spatial and political settings. The implementation of the proposed research method means that the research field includes, firstly, finding some common, accepted as normative prerequisites of inter-ethnic relations' management. Secondly, there is a network of exchanging values and meanings, which are given the managing (conducting) effect.

Aiming at the ethnic-oriented dialogue and ethnic communication itself requires overcoming the backgroundcentrism. In order to reconstruct the theoretical picture, it is important to identify the "truth of intention", which means aiming at the study of ethnic relations management as a system of relations among the subjects that is included in the process by public institutions, civic associations, ethnic and social communities.

Within the stated problem, one must understand the paradoxical essence of such phenomena as ethnic relations control being out of discourse and the reality of the aspiration to achieve the rational consent about norms and values integrating the society.

\section{Results}

Noting that the inter-ethnic relations management does not include the state of conflict absence as an ultimate goal explicitly, we can say that management is mainly treated as an integration into the civil society. This conclusion is firstly proven with the fact that in relation to the management, the emphasis is made on either associated partnership with the state through the procedures of distribution of competence and resources or on defining the limits of civil (local) initiative, able to inspire the intercultural dialogue.

Typically, the ethnic communities are given the status of a conditional partner. It is not about the subjectivity of the ethnic community but about its representation through structures with a high degree of loyalty to the values of the host society. The difficulty arises, which can be overcome procedurally, but which has ambiguous consequences in a meaningful context. It is expressed in the fact that some associations, selected as partners representing ethnic commonality, may not be perceived as such in the ethnic environment and enjoy no trust concerning the delegation of interests.

In Germany, where the Turkish community has the longest history, one can observe how the attempts to organize an inter-ethnic dialogue at the level of intellectuals who share European values, create a situation of distancing from participation in a dialogue between the resistance groups, whose position is skeptical by virtue of the argument that Turks are not present in the dialogue - only the "converted Germans" are. Obviously, the internal colonization discourse is there, a transfer of the cultural superiority scheme concerning European values onto the inter-ethnic relations.

A Russian researcher E. Filippova admits that talking in terms of maintaining diversity is to follow the model of civilizations clash (Demintseva, 2013). This remark is appropriate concerning the fact that there is a contradiction between "differences management " and creating the necessary conditions for a political community. If to take the cultural difference as an unconditional value, then the equity sign can be placed between ethnic (particular) values and civilian ones claiming to be universal. Since the differences are perceived as a doubtless condition of ethnic identity preservation, it is impossible to form a "fan" of values, to build a hierarchy of values policy or to explain the mechanisms of ethnic units' transferring into the collective intelligence.

An unpleasant situation occurs, because the civic values are given the importance of cultural superiority, while the ethnic values can be interpreted in the context of archaism, backwardness, lack of progress. There is a risk of cultural exclusion and isolation strengthening, because even at the local level tension and "misunderstanding" are obvious. There is no space for the dialogue, because the speech partner tends to follow a similar procedure of absolutization of cultural differences and to consider their leveling as a threat to the ethnic community itself.

Thus, in the inter-ethnic relations management the state of uncertainty is achieved: building up successful communication technologies at the local level, involving the adoption of a formula of coexistence, does not mean that the stated goal of integration is set at the state level. Some semantic confusion is introduced not by the mere fact of ethnic diversity recognition, which has the cultural meaning in the official discourse, but the fact that there is an aspiration in the ethnic environment to use the cultural diversity for political argumentation. The concern is that accepting the formula of an ethnicity and the host country being equal partners, there comes a desire to institutionalize ethnic differences, the desire to change the state of positive discrimination for ethnic values' legitimization because these values don't lose in their symbolic and political capital to common civil virtues.

It is obvious that in the ethnic relationship management construct, the preset idea/aim concerning the procedural aspect plays a bad role: it is believed that the State's impartiality towards a culture of individual groups prohibits the State to use mechanisms of coercion and influence for ideological indoctrination. If the State is governed by the logic of equity, expectations are based on the fact that, the State would be involved into the management of inter-ethnic relations only as 
a legal guarantor and would ensure equal access to material and institutional resources. Yet the paradox of control, though not being put into the public discourse, is in that the obligations entrusted to the State can be "compensated" only by the faith in pursuit of inter-ethnic dialogue and interethnic communication between the potential participants of this process.

Meanwhile, as the experience of Germany shows, Islamist structures quite adequately use support options at both local and, partly, regional levels, in the fields of information, education and culture. Moreover, the mere use of resources from the authority, which is not accepted as a legitimate one, strengthens confidence in the objectivity of the chosen strategy of integration resistance.

Rather, as the American researcher M. Uoltser writes, the management model, which is based on the idea of the State as about some supra-national unification (Demintseva, 2013) may be effective at the level of individual actions, but the decentralized nature of administration relies on the disputable idea of non-violent co-existence of ethnic communities.

A pre-rational element of inter-ethnic relations control can be considered the fact that the commonalities are associated not with the ethnic and religious aspects, but represent the groups of citizens opting for civic virtues. Meanwhile, whatever is said about the unacceptability of ethnic corporativism, a desire to reach the addressee, to form backward linkages "collapses", if not to take into account that the management impact- if not to assess it as effective but to use the optimality criterion-is based on the definition of resistance or cooperation measure on the part of the ethnic community. As the control system eliminates the possibility of addressing the ethnic community as a potential partner, and the task in the context of the dialogue becomes to reach a state of integration, there may be individual successes along this way, which do not reduce the ethno-cultural distance. At the same time, we should not unconditionally claim that the implemented integration model in the management of inter-ethnic relations can be a subject to the total critics.

With that, the public discourse often, apparently for political competition, argues that the "soft integration" is obviously ineffective if through the transference of ethnicity into, cultural differences, explicitly in the management of inter-ethnic relations, although the cultural identity hasn't been achieved and the phenomenon of a split up society can occur (Pugacheva, Filippov, 2013), a legal identity contains the possibility of political revenge and therefore, it limits the destructive impact of the cultural differences promotion when becoming political demands.

At least the assertion that democracy requires the elimination of heterogeneity can hardly be updated in the conditions of the open society and a tolerant attitude towards cultural as individual differences.

This observation is significant, if to expect the change of inter-ethnic relations control vectors: a critique of multiculturalism does not mean abandoning the idea of cultural diversity: another thing is that in the inter-ethnic relations management system an important fact was forgotten that in the current conditions the repetition of the Nouveau experiences associated with of ethnic minorities assimilation (Bretons in France, Wales in the UK, Frisians in Germany) cannot be considered successful. Ethnic communities representing the diaspora formations, first "are stuck" to the ethnic identity but only as a tool for preservation of the cultural and ethnic identity. In a broader context, they actualize the ethnicity in the political space not necessarily acting in association with traditional political structures.

Given the variety of relationships with the historical homelands, which authorities seek to exploit the diaspora for lobbying their own interests, one can say that the opposition to the modernism experience is also in that managing cultural differences more often leads to the use of the ethnic memory resource than to the separation of universally political and particularly cultural. The cultivation of differences has the consequence of recourse to the historical motherland not only as a symbol of ethnic continuity, but also in the context of awareness of one's otherness through the imaginary citizenship with the historical motherland.

Described by German researchers, the phenomenon of German Arabs' persistence to stick to their ethnic identity, is largely determined by the fact that in addition to continuing relationships with the ethnic homeland, reproduction of the unity with the Arab nation is essential, from the position of dignity, according to which the Arabic ethnic group in Germany is not the migrants ' quazi-union, but represents a civilization, having, at the very least, influence and prestige by the degree of historical genealogy. What might be called a revibalization of the religious (Islamic) identity happened due to the fact that in managing inter-ethnic relations, religious differences became perceptible in the disputed context of the "attitude to religion as to a private matter", and that the mosque became the symbol of deethnization: in reality, the senses of "ummah" of the Islamic community did not become an alternative to the ethnic radicalism. If the nationalists can be discussed within the framework of secular terminology, Islamization results in ethnic differences being changed into the consolidation of civic values rejection.

Of course, if to have a dialogue with the ethnic groups, the probability of confrontation on procedural questions is high, but the imposition of a religious identity creates a problem of integration proposals under the new rules: the rules dictated by religiosity growth in a society where religious traditions are almost lost. Achieving an acceptable level of consensus on the public policy level can be considered theoretically possible, based on the logic of legal equity, but 
practically difficult because of the questioned mandatory affiliation to a civil (political) community.

This is understood in the context of thinking about the inter-ethnic relations experience. S. Huntington expressed anxiety concerning the Americanism bastion - civil religion-being associated with the national approach (Huntington, 2004). This means that the recognition of the culture, values and traditions of other societies defines the vector of interethnic relations management through support of American identity and thus through return to the model of ethnic groups' assimilation.

S. Huntington's worry seemed to cause no approval in the American society or in the scientific community: it was perceived as a vestige of religious conservatism. There is, however, a reason to believe that in the management of interethnic relations, the formula of national unity becomes important, the adoption of legislative acts on American patriotism, as well as the expansion of competence in the ethnic processes management by "American values supporters " (patriotic masses against the cosmopolitan elites) is evidently expressed in the "California incident", described by Huntington: the elite, supporting the idea of cultural diversity, is not ready to abandon racial privilege. The elite's position cosmopolitanism is the desire to maintain the social and racial discrimination on the basis of its explanation by the "inborn" cultural differences. In managing inter-ethnic relations, Huntington had an aim to "americanize" ethnic groups, basing on the core values.

Yet such a scheme can be realized, if cultural differences are interpreted only as the domain of privacy. The practiced procedure of cultural differences management ("salad-bowl" model) contains a visible effect of the tolerance introduction but its positive impact ends where cultural differences are introduced into the political discourse. Returning to the model of integration both in Germany and in the United States is connected with the recognition of ethnic homogeneity as a problem of the social security and stability, which explains considering the refusal from concept of civil values universalism legitimate in the scientific discourse.

It's legitimate in the sense that the management of inter-ethnic relations is derived from the global context and correlates with national interests, although the discourse of Europeanization is accepted as a guidance in ethnic relations. Normalization means inculcation love for the new homeland and its culture. The tightening language policy, the compulsory character of the language competence of all the new German citizens become understandable, as well as the boycotts of the idea of official bilingualism in States with a large Hispanic minority becomes compatible.

In other words, proclaiming the idea of cultural diversity promoting on the basis of the recognition of the civil (political) nation supremacy, in the management of inter-ethnic relations a priority is given not to the legal regulation, but to ideological and value politics, to the integration model, connected with the acceptance of the values characterizing the national identity. In the context of competing claims on monopoly in managing inter-ethnic relations, a movement towards internal consolidation is becoming clear.

Strengthening of the ethnic heterogeneity is not regarded as an act of external appropriation and discouraged as a new citizens' finding. The need for fidelity to the traditions and values of the host community is admitted to be essential, which is difficult in the Germany situation within the framework of European integration and suspicion on the part of foreign partners concerning the restoration of Great German nationalism. However, in this situation, as Sh. Rodewald writes, though he appeals to the Russian experience, a public representation of the inter-ethnic politics is determined by the "imaginary internal colonization of the external one". It is a way to legitimize the ethnic groups' integration as an event of internal life in isolation from the ethnic homeland and an end to the debate over how the new citizens can combine their hereditary ethnic identity with the newfound German one.

And since the implemented terminological modification of inter-ethnic relations management has a reason, if the host society is identified with ethnic groups, the cultural and language policies can be represented as out-of-ethnic, i.e. the German language and the German culture are becoming a social nomination procedure, that is, as the French sociologist P. Bourdieu wrote, they create a sense of position, a sense of boundaries of "one's own" and "others'" (Bourdieu, 1993). Inter-ethnic relations are structured on the basis of recognized differences, the differences that contribute to the legitimate and proven differentiation that is associated with the stages of civil and political loyalty.

It should be noted that in the management of inter-ethnic relations in Germany, although the formula of national unity is not so distinctly expressed as in the United States, the willingness to admit the official classification opportunities meaningful is obvious; the right of the government structures to counter the political extremism by summing up under the criterion of legitimacy. Thus, in the inter-ethnic relations management there is practice of unifying the symbolic (cultural) "market" to help alleviate the isolationist sentiment, but at this the effect of politicization is mainly visible in its radical form.

There is a certain gap between the theoretical ideas and actual practices, especially at the local level: public policy legalism brings theory to explain the positive discrimination, but in this context, a wish to introduce the communicative rationality as a criterion for intercultural dialogue establishing is contrasting.

Indeed, the ongoing local projects are connected with the partnership, breaking the public silence. While 
management theory is reflecting about the legal regulation, the real practices are associated with the institutionalization of ethnicity, i.e. the recognition of ethnic groups' right to determine conditions of joint activities through a dialogue of cultures.

It cannot but create a precedent of "pressure" when the reference to cultural differences can take the form of conflict (a ban on Christian holidays celebration). Thus, the ethnic relations are objectively interpreted as primordialist, i.e. at the level of similarity of mental and cultural characteristics. The duality of management is rationally justified, related to the fact that the management of cultural differences is appropriate for inclusion. The meaning of such a provision is that cultural differences are understood as invented, constructed in accordance with the objectives of integration (substitution of Islam with Euro-Islam).

At the same time, it is believed that radicalization of cultural differences has to be condemned, and the proclamation of the cultures dialogue does not require any deep revision of ethnic relations management, as in interethnic communication frames, the differences are "natural" and, most importantly, do not contain the heavier value of distancing. If management is revised it happens in moderating multiculturalism as making the cultural differences absolute. The fact is that with the introduction of positive discrimination policies, ethnic communities can be categorized as minorities, which need to protect their minority rights. This eliminates the problem of legal status obtaining and thus saves the formula of management decentralization as the impact on cultural forms' development.

\section{Conclusion}

In the process of analyzing the existing content management of inter-ethnic relations, there appears an association with overcoming post-colonial times, the fact that control systems' vector may vary depending on the ideology of the legal equity, the fact that theoretical egalitarianism commits to abandoning the formula of national identity to block suspected political discrimination. In other words, the objectives of the inter-ethnic relations management are "idealistic", simultaneously limiting the possibility of applying concepts "ethnos", "ethnic group", focusing on quazi-commonness, and unstable groups of cultural preferences.

Meanwhile, the important point is that adoption of cultural identity as a conceptual representation of the subject's construction of ethnic relations, promotes ethnization recidive in sufficiently unpredictable forms, appeal to the archaic ethnic elements, creating not so much risk of racism but leading to a semantic boomerang as substitution with the religious identities.

\section{Acknowledgement}

This article was financially supported by the grant of the Russian Science Foundation No. 15-18-00122 "Institutional practices and value policy in the sphere of harmonization of interethnic relations in the economically developed countries with complex ethnic and cultural structure: comparative analysis and modeling of implementation in the Russian context".

\section{References}

Delanty, G. (2006) Europe and Asia beyond East and West. London: Routledge.

Diamond, L. (1999) Developing Democracy. Towards Consolidation. Baltimore and London: The Johns Hopkins University Press.

Haynes, J (2005) Comparative Politics in Globalizing World. Cambridge: Polity.

Burd'e, P. (1993) Sociologiya pilitiki. M., p. 65 [in Russian]

Darendorf, R. (2003) Sovremenniy sotsial'niy konflikt. Ocherki politiki svobody. M.: Russian political Encyclopedia. [in Russian]

Demintseva, E. (ed) (2013) Rasism, ksenofobiya, descriminatsiya. M.: Novoye literaturnoye obozreniye. P. 87 [in Russian]

Pugachyova, M.G. \& Philippov, A.F. (obtsch.red.) (2015) Puti Rossiyi. Alternativy obtschestvennogo razvitiya. M. P.262 [in Russian]

Hantington, S. (2004) Who are we? M., P.569. 